\title{
ASSESSING STUNTING AND PREDISPOSING FACTORS AMONG CHILDREN
}

\author{
ANIL GUPTA* \\ Department of Physiology and Biochemistry, Eklavya Dental College \& Hospital, Kotputli, Rajasthan, India. \\ Email: anilfzk2323@yahoo.com
}

Received: 05 August 2017, Revised and Accepted: 10 August 2017

\section{ABSTRACT}

Objective: The present study was aimed at "assessing stunting and predisposing factors among children."

Methods: Prospective, descriptive, observational and cross-sectional study was conducted comprising children between 2 years and below 5 years age group in the city Fazilka in Punjab, India. Random, two-stage cluster sampling method was adopted. Direct observation and interview methods were used to assess physical appearance, demographic characteristics, habit of soil eating, and episodes of diarrhea (diarrheal episodes 2 weeks before investigation). Inspection method was used to assess nail beds of children to ascertain pallor.

Results: Prospective, descriptive, observational and cross-sectional study was conducted comprising children between 2 years and below 5 years age group in the city Fazilka in Punjab, India. Study population was made up of total 440 children which were differentiated into $240 / 440,127 / 440$, and $73 / 440$ children representing about $54.5 \%, 28.9 \%$, and $16.6 \%$ of proportions from schools, child care, and slums, respectively. Children $55 / 240$, $36 / 127$, and $35 / 73$ from schools, childcare centers, and slums suffered from stunting which amounted to about $23 \%$, $28 \%$, and $48 \%$ prevalence of stunting in school, childcare center, and slum children. Gender-wise characterization of study population depicted boys (260/440) and girls (180/440) with a proportion of $59 \%$ boys and $41 \%$ girls. Among the participants, about $20.5 \%(90 / 440)$ and $79.5 \%$ (350/440) of children belonged to illiterate and literate parents. The odds for stunting were nearly 1.6 times higher among anemic children in comparison to children in non-anemic group represented by odds 0.575 and 0.348 in former and latter groups of children with odds ratio (OR=1.65). Children ( $\mathrm{n}=41)$ out of total children $(n=80)$ those belonged to income (<2000 INR) per month in family, were stunted and contributed to $51 \%$ prevalence of stunting. Another group of children ( $\mathrm{n}=85 / 360$ ) who belonged to income ( $>2000$ INR) per month in family, suffered from $23.6 \%$ prevalence of stunting.

Conclusion: National policies should be reformed to generate employment, Maintain minimum support price for Agricultural products, Sustain food security and contribute and promote community sanitation and hygiene.

Keywords: Stunting, Malnutrition, Anemia, Undernutrition, Diarrhea.

(C) 2017 The Authors. Published by Innovare Academic Sciences Pvt Ltd. This is an open access article under the CC BY license (http://creativecommons. org/licenses/by/4. 0/) DOI: http://dx.doi.org/10.22159/ajpcr.2017.v10i10.21116

\section{INTRODUCTION}

Stunting is the discrepancy in height for age and characterized by a deficit in linear growth of a child. It is determined as the height for age of a child below ( $<-2$ standard deviation [SD]) of the median of the reference population and is the after effect of long-standing inadequacy in nutrition or sanitation or disease or hygiene, thereby, portraying a cumulative ill effect on the linear growth of body which might persist even after the termination of the etiological factor. Stunting is an indicator of chronic malnutrition and is the chief health impediment among children below 5 years of age affecting around 165 million children globally by 2011 [1].

Chronic malnutrition is the consequence of poverty, food insecurity, hunger, and/or disease. According to a report, around 1.3 billion population of world survive in extreme poverty and dilapidated health status [2]. Morbid living conditions, poor sanitation and unhygienic food preparation and consumption, lead to persistent enteric infection among actively growing children in developing countries. Authors have postulated that every child under 5 years of age suffer from an average three diarrheal episodes in a year, prominently in developing countries [3].

Irrevocable poverty and living condition are disposed into perpetuated poor environmental conditions, which additionally, predispose to persistent diarrhea among children. This gastrointestinal disorder may manifest into impaired linear growth, poor psychomotor development [4].
Authors have described that diarrhea and respiratory infection in children are potentially harmful to their normal linear growth $[5,6]$. Malnourished children could have growth pattern similar to that of nourished children; however, sustained diarrhea and other infections resulted into distorted growth pattern. This event is highly pronounced in the $2^{\text {nd }}$ year of life. Its ill effects are maintained in later periods of childhood $[5,6]$. According to a report, poor quality of drinking water, poor sanitation, and hygiene is responsible for major proportion of malnutrition and diarrhea [7]. Poor diet is the additional factor for undernourishment.

Food insecurity is linked to stunting and impoverished child growth and development. It is the insufficiency in quantity and quality of nutritious foods and/or the incapability to procure nutritious foods in adequate quantity and quality for the family members. Household food insecurity is involved in short-term and long-term negative ill effects on the physical and mental health of children in period of rapid growth.

Illiteracy, monthly income of household and diseases have profound effect on the health of preschool children.

\section{Rationale of study}

Paucity of information concerning factors related to stunting among preschool children in the city, Fazilka in India, together with the absence of any authentic prevalence study previously, motivated to conduct this study. 


\section{Objectives of study}

- To assess prevalence of stunting among children between 2 years and below 5 years of age in Fazilka city in India.

- To assess factors associated with stunting among children between 2 years and below 5 years of age in Fazilka city in India.

- To predict correlation between stunting and predisposing factors among children between 2 years and below 5 years of age.

\section{METHODS}

\section{Research design}

Prospective, descriptive, observational and cross-sectional research design was adopted for this study.

\section{Sampling design}

Study area

Study was conducted in Fazilka city in Punjab state in India. The city is situated on Indo-Pak border in Punjab state. According to Census of India, 2011 , it has a population of 67,424 , with $52 \%$ males and $48 \%$ females. Children below 6 years of age constituted around 13\% of the population.

\section{Sample frame and sampling unit}

Children between 2 years and under 5 years of age, who were residents of Fazilka city, together constituted sample frame. Children, who were qualified by sample selection criteria, formed the sampling units.

\section{Sample selection criteria}

Inclusion criteria

- Children between 2 years and below 5 years of age group

- Children who were resident of Fazilka city in Punjab in India

- Girls and boys were eligible for study

- Children who obliged in physical examination and anthropometric measurement.

Exclusion criteria

- Children, who were either below 2 years and/or above 5 years of age, were excluded from study

- Children who were critically il

- Children, who were fearful and crying on approaching the investigator, were excluded from the study.

\section{Sampling methods}

Random, two-stage cluster sampling method was adopted.

In the first stage, the city was categorized into three strata, as:

- Elementary schools

- Childcare centers

- Slum areas.

Schools, childcare centers, and slums were selected randomly from the sample frame.

In the second stage, all children who fulfilled sample selection criteria were selected for the study.

\section{Sample size determination}

Sample size was determined, according to the following formula:

Sample size $(\mathrm{n})=\mathrm{Z} 2 \times \mathrm{p} \times \mathrm{q} / \mathrm{d} 2$

$\mathrm{Z}=$ Value of 1.96 was used at $95 \%$ of confidence interva $\mathrm{p}=47 \%$ prevalence of malnutrition

$\mathrm{q}=(1-\mathrm{p})$

$d=5 \%$ margin of error

Sample size of 382 was calculated.
To this sample size, non-response rate of $15 \%$ was added. Therefore, after final adjustment, sample size of 440 was determined.

\section{Data collection design}

Type of data

- Primary data were collected for analysis.

\section{Data collection instrument}

Observation and interview schedules were used for recording demographic characteristics, anthropometric measurement and clinical signs.

\section{Data collection technique}

- Direct observation and interview methods were used to assess physical appearance, demographic characteristics, habit of soil eating, and episodes of diarrhea (diarrheal episodes 2 weeks before investigation)

- Inspection method: Nail beds of children were examined to ascertain pallor.

- Anthropometric measurements

- Height was measured using a vertical wooden height board. Children were placed on measuring board and asked to stand upright in the middle of the board. The child's head, shoulders, buttocks, knees, and heels were made to touch the board. Height was recorded in centimeter units.

- Weight was measured by a weighing scale. It was calibrated every time. Child was asked to stand on the scale barefooted with light clothing. Weight was recorded in kilogram units.

Scales

- Interval scale was used for recording age, weight, and height of children

- Pallor, stunting, geophagy, illiteracy, monthly income, and diarrheal episode were described in prevalence.

Prevalence of a variable=Number of participants affected/total number of participants $\times 100$

Cut offs

- Height for age of participants was expressed in standard deviation, as recommended by the WHO [8].

- The standard deviation (<-2SD) was implied as cutoff point for defining stunting, as recommended by the WHO [9]

Study variables

- Dependent variable

- Stunting was considered as a dependent variable.

- Independent variables:

- Age: Study population was categorized into 2-3 years and $>3-<5$ years age groups

- Gender

- School, childcare center, and slum

- Income of household per month

All houses categorized into monthly income of $<2000$ INR and $>2000$ INR.

- Education of parents: Inability to read or write was considered positive for illiteracy

- Anemia in children: Pallor of nail beds was implied as a clinical sign to ascertain anemia in children

- Diarrhea: History of diarrheal episode 2 weeks before time of investigation, was considered positive for diarrhea

- Geophagy: History of eating soil, chalk, paper was considered positive for the presence of geophagy habit among children. 


\section{Ethical approval}

Approval was taken from the principal of institution for conduction of postdoc research.

\section{Consent}

Objectives of the study were explained to parents of children in slum areas, guardians and childcare givers in schools and child care centers. Oral consent was obtained from the parents in slums, guardians, and child care givers. It was promised to keep the identity of participants confidential.

\section{Statistical design}

Descriptive analysis

Data were summarized into tables.

Study variables were described in terms of frequency $(\mathrm{n} / \mathrm{N})$, percentage (n\%), and prevalence.

\section{Correlation analysis}

Odd ratio was computed with 95\% confidence interval (CI).

\section{Inferential analysis}

Hypothesis testing done by Chi-square test for independence and $\mathrm{p} \leq 0.05$ was implied as statistically significant.

\section{RESULTS}

\section{Demographic study}

Study population was comprised total 440 children between 2 years and below 5 years of age group. Children 240/440,127/440, and 73/440 were selected from schools, child care centers and slums, respectively, as shown in Table 1. Schools, child care centers, and slums contributed to $54.5 \%, 28.9 \%$, and $16.6 \%$ of children, as shown in Table 1 . Genderwise characterization of study population described 260/440 and 180/440 boys and girls, respectively, as depicted in Table 1 and it was represented by (59\%) boys and (41\%) girls.

Study population was categorized into $2-3$ years and $>3-<5$ years age groups. Former age group was made up of 169/440 children, and latter age group was formed of 271/440 children, as shown in Table 1. Age categorization provided $38 \%$ and $62 \%$ of children in $2-3$ years and $>3-<5$ years age groups, as shown in Table 1 .

In the study population, about $20.5 \%$ (90 children out of total 440 ) and another $79.5 \%$, ( 350 children out of total 440 children) of children belonged to illiterate and literate parents, respectively, as shown in Table 1 . The income characterization of study population showed that $18 \%$ (80/440) and $82 \%$ (360/440) of children belonged to families with an income of rupees $\leq 2000$ and rupees $>2000$ per month, as shown in Table 1 .

\section{Age groups of children and stunting \\ Descriptive analysis}

Children $(n=68)$ out of total children $(n=169)$ were stunted with a prevalence of $40 \%$ in the age group (2-3 year), as Table 2 depicted. The other age group $(>3-<5$ years) had $(n=58)$ children out of total $(n=271)$ children and amounted to around $21 \%$ of prevalence, as shown in Table 2. Around $60 \%(101 / 169)$ of children in age group (2-3 year) and about $79 \%(213 / 271)$ children in $>3-<5$ year age group were healthy, as shown in Table 2. The overall prevalence of stunting was $28.6 \%(126 / 440)$ in children between 2 years and below 5 years of age. Moreover, age groupwise prevalence of stunting was higher $(40 \%)$ in $2-3$ years and low $(21 \%)$ in $>3-<5$ years age groups, respectively.

\section{Correlation analysis}

In age group (2-3 years), odds of having stunting in children were 0.67 (68/101), whereas, odds $0.27(58 / 213)$ for stunting in children were predicted in age group $(>3-<5$ years) as shown in Table 2 . The ratio of the odds of former group to the odds of latter group was
$2.47(0.67 / 0.27)$ at $95 \% \mathrm{CI}$ with an upper limit (1.58) and lower limit (3.86), as shown in Table 2. The children in (2-3 years) age group exhibited 2.47 times higher probability of becoming stunted in comparison to children in $>3-<5$ years age group. The $95 \% \mathrm{CI}$ for higher stunting probability in children in $2-3$ years age group is $>1$. This correlation was statistically significant.

\section{Inferential analysis}

Inferential analysis was performed by Chi-square test of independence. The test statistics $\left(\chi^{2}=18.07\right.$ at $\left.\mathrm{df}=1\right)$ exceeded the critical value of Chi-square $\left(\chi^{2}=3.84\right.$ at $\left.\mathrm{df}=1\right)$, as in Table 2 . Further, $\mathrm{p}<0.001$ of test statistic was much less than the implied $(\mathrm{p}<0.05)$. Therefore, alternate hypothesis was accepted at $5 \%$ significance level.

\section{Gender characterization of study population and stunting Descriptive analysis}

About 63 boys out of 260 boys and same number of girls 63 out of 180 girls were stunted as depicted by Table 3, which constituted about $24 \%$ and $35 \%$ of prevalence of stunting in boys and girls, respectively, as shown in Table 3. Additionally, (197) boys and (1170 girls were normal out of total of (260) boys and (180) girls which amounted to about $76 \%$ and $65 \%$ normal boys and girls, respectively, as in Table 3. Moreover, the prevalence of stunting in girls (35\%) was higher in comparison to $24 \%$ of prevalence of stunting in boys.

Table 1: Demographic characteristics of study population

\begin{tabular}{lll}
\hline Characteristics & Frequency (n/N) & Proportion (n\%) \\
\hline Schools & $240 / 440$ & 54.5 \\
Child care centers & $127 / 440$ & 28.9 \\
Slums & $73 / 440$ & 16.6 \\
Boys & $260 / 440$ & 59 \\
Girls & $180 / 440$ & 41 \\
Age group (2-3 years) & $169 / 440$ & 38 \\
Age group( $>3-<5$ years) & $271 / 440$ & 62 \\
Illiterate parents & $90 / 440$ & 20.5 \\
Literate parents & $350 / 440$ & 79.5 \\
Income of family/ & $80 / 440$ & 18 \\
month ( $\leq 2000$ Rs) & & \\
Income of family/ & $360 / 440$ & 82 \\
month (>2000 Rs) & &
\end{tabular}

Table 2: Age groups of children and stunting

\begin{tabular}{lll}
\hline Characteristics & $\begin{array}{l}\text { Children } \\
(\mathbf{2 - 3} \text { year) } \\
(\mathbf{n = 1 6 9 )}\end{array}$ & $\begin{array}{l}\text { Children } \\
\mathbf{1} \\
(\mathbf{n = 2 7 1}-\mathbf{5} \text { year) }\end{array}$ \\
\hline Stunted children & $68(40 \%)$ & $58(21 \%)$ \\
Normal children & $101(60 \%)$ & $213(79 \%)$ \\
Odds ratio & 2.47 & \\
95\% Confidence interval & $1.58-3.86$ & \\
Chi-square value $\left(\chi^{2}\right)$ & 18.07 & \\
p $\leq 0.05$ & $<0.001(\mathrm{HS})$ & \\
\hline
\end{tabular}

HS: Highly significant

Table 3: Gender characterization of study population and stunting

\begin{tabular}{lll}
\hline Characteristics & Girls (n=180) & Boys (n=260) \\
\hline Stunted children & $63(35 \%)$ & $63(24 \%)$ \\
Normal children & $117(65 \%)$ & $197(76 \%)$ \\
Odds ratio & 1.68 & \\
95\% Confidence interval & $1.109-2.556$ & \\
Chi-square value $\left(\chi^{2}\right)$ & 6.04 & \\
p $\leq 0.05$ & $0.01(\mathrm{~S})$ & \\
\hline
\end{tabular}




\section{Correlation analysis}

In the girls, odds of becoming stunted was $0.538(63 / 117)$, while, the odds of being stunted in boys were $0.319(63 / 197)$. The ratio of the odds of stunting in girls to the odds of stunting in boys was $1.68(0.538 / 0.319)$ as shown in Table 3 with $95 \% \mathrm{CI}$ in the range (1.109-2.556). Hence, the possibility of stunting in girls was 1.68 times elevated in comparison to stunting probability in boys, as shown in Table 3. Consequently, female predisposition toward stunting was correlated significantly.

\section{Inferential analysis}

Chi-square test of independence was performed for hypothesis testing, and test statistics yielded $\left(\chi^{2}=6.04\right)$, and it was greater than the critical value $\left(\chi^{2}=3.84\right)$ with degree of freedom (df) $=(1)$ at $95 \%$ CI. The $p=0.01$ of test statistics was lesser than implied $\mathrm{p}=0.05$. Therefore, alternate hypothesis was accepted at $5 \%$ significance level, as shown in Table 3.

\section{School, child care center, and slum children and stunting Descriptive analysis}

Children 55/240, 36/127, and 35/73 from schools, child care centers, and slums were observed suffering from stunting, as shown in Table 4 and amounted to about $23 \%, 28 \%$, and $48 \%$ prevalence of stunting in children in school, child care centers, and slums. Moreover, 77\% (185/240), 72\% (91/127), and 52\% (38/73) of children in schools, child care centers, and slums observed with normal height for age, as shown in Table 4.

Prevalence of stunting in slum children (48\%) was much higher in comparison to stunting prevalence in children from schools $(23 \%)$ and child care centers $(28 \%)$.

\section{Inferential analysis}

Chi-square test of independence was conducted to test the hypothesis. Test statistics provided $\chi^{2}=17.2$ value, which was very high in comparison to critical value $\chi^{2}=3.84$ at degree of freedom $(\mathrm{df}=1)$. The computed $\mathrm{p}=0.0002$ from test statistic was very low in comparison to implied $\mathrm{p} \leq 0.05$, as shown in Table 4 . As a result, alternate hypothesis was accepted at $5 \%$ significance level.

\section{Anemia (pallor) in children and stunting \\ Descriptive analysis}

Out of total 440 children in the study group, about $(n=115)$ children suffered from anemia (pallor), and other (325/440) children were normal, thereby, represented about $26 \%$ prevalence of anemia in children between 2 years and below 5 years of age group. Further, around 42 anemic children were stunted out of total 115 anemic children, as shown in Table 5. Descriptive analysis described about $36.5 \%$ prevalence of stunting in anemic children. In addition, about $63.5 \%(n=73 / 115)$ anemic children had normal height for age. In the non-anemic group, 84 children out of total 325 were stunted with a $25 \%$ prevalence of stunting, as depicted in Table 5. Other (241/325) children in non-anemic constituted $75 \%$ normalcy in height for age parameter. Overall, higher prevalence of stunting (36.5\%) was observed in anemic group of children in comparison to $25 \%$ prevalence in non-anemic group of children.

\section{Correlation analysis}

Odds ratio was computed to assess the correlation between anemia (pallor) and stunting in children. In anemic group of children, the odds of being stunted were 0.575 , whereas, in non-anemic group of children, the odds of becoming stunted were 0.348 , as shown in Table 5 . The ratio of odds between former group and latter group was $1.65(0.575 / 0.348)$. The $95 \%$ CI was $>1$ with its upper limit (1.02) and lower limit (2.66), as shown in Table 5. Correlation between stunting and anemia (pallor) was significant at $95 \%$ confidence level.

\section{Inferential analysis}

Test statistics furnished $\left(\chi^{2}=4.7\right)$ value of Chi-square test of independence, which was greater than the table value $\left(\chi^{2}=3.84\right)$ at $\mathrm{df}=1$, as shown in Table 5. In addition, $\mathrm{p}=0.03$ from test statistics was lesser than implied $p=0.05$; hence, higher prevalence of stunting in anemic group of children was significant.

\section{Habit of soil eating (geophagy) and stunting among children} Descriptive analysis

Out of total 440 child participants in the study population, around 41 children were afflicted with habit of soil eating (geophagy) afflict, as shown in Table 6 and it amounted to 9.4\% prevalence of habit of soil eating in children between 2 years and under 5 years of age. Children (399/440) were normal in terms of eating habit. Furthermore, 21 children out of 41 children with habit of soil eating were stunted constituting a prevalence of around $51 \%$, as shown in Table 6 . Conversely, 105 children out of 399 children without habit of soil eating had prevalence of $26 \%$ stunting. Other 20 children with soil eating habit and 294 children without soil eating habit had normal height for age anthropometric parameter. Prevalence of stunting (51\%) was much higher in children with habit of soil eating in comparison to prevalence $(26 \%)$ of stunting in children without habit of soil eating.

\section{Correlation analysis}

Odds ratio was computed. Odds of becoming stunted were 1.05 in children with habit of soil eating and odds of being stunted were 0.375 in children without habit of soil eating. The computed odds ratio was 2.9, as exhibited in Table 6. Children with habit of soil eating were exposed to 2.9 times higher probability of becoming stunted in comparison to children without habit of soil eating. Since 95\% CI was higher than $(>1)$, hence, correlation between habit of soil eating and stunting was significant at $\mathrm{p}=0.05$.

Table 4: School, child care center, and slum children and stunting

\begin{tabular}{lll}
\hline Characteristics & $\begin{array}{l}\text { Stunted } \\
\text { children }\end{array}$ & $\begin{array}{l}\text { Normal } \\
\text { children }\end{array}$ \\
\hline Schools $(\mathrm{n}=240)$ & $55(23 \%)$ & $185(77 \%)$ \\
Child care centers $(\mathrm{n}=127)$ & $36(28 \%)$ & $91(72 \%)$ \\
Slums $(\mathrm{n}=73)$ & $35(48 \%)$ & $38(52 \%)$ \\
Chi-square value $\left(\chi^{2}\right)=17.2$ & & \\
$\mathrm{P}(\leq 0.05) 0.0002(\mathrm{HS})$ & & \\
\hline
\end{tabular}

HS: Highly significant

Table 5: Anemia (pallor) in children and stunting

\begin{tabular}{lll}
\hline Characteristics & $\begin{array}{l}\text { Anemic } \\
\text { children }(\mathbf{n = 1 1 5})\end{array}$ & $\begin{array}{l}\text { Non-anemic } \\
\text { children }(\mathbf{n}=\mathbf{3 2 5})\end{array}$ \\
\hline Stunted children & $42(36.5 \%)$ & $84(25 \%)$ \\
Normal children & $73(63.5 \%)$ & $241(75 \%)$ \\
Odds ratio & 1.65 & \\
95\% Confidence interval & $1.02-2.66$ & \\
Chi-square value $\left(\chi^{2}\right)$ & 4.7 & \\
p $\leq 0.05$ & $0.03(S)$ & \\
\hline S: Significant & &
\end{tabular}

Table 6: Habit of soil eating and stunting among children

\begin{tabular}{lll}
\hline Characteristics & $\begin{array}{l}\text { Children with } \\
\text { habit of soil } \\
\text { eating (n=41) }\end{array}$ & $\begin{array}{l}\text { Children without } \\
\text { habit of soil } \\
\text { eating (n=399) }\end{array}$ \\
\hline Stunted children & $21(51 \%)$ & $105(26 \%)$ \\
Normal children & $20(49 \%)$ & $294(74 \%)$ \\
Odds ratio & 2.9 & \\
95\% Confidence interval & $1.46-5.91$ & \\
Chi-square value $\left(\chi^{2}\right)$ & 11.3 & \\
p $\leq 0.05$ & $0.001(\mathrm{HS})$ & \\
\hline
\end{tabular}

HS: Highly significant 


\section{Inferential analysis}

Chi-square test of independence provided $\chi^{2}=11.3$ and it was higher than table value $\left(\chi^{2}=3.84\right)$ at $\mathrm{df}=1$. Further, test statistics had significance $(p=0.001)$ level and it was much lower than implied significance ( $\mathrm{p}=0.05)$, as shown in Table 6 . Hence, alternate hypothesis was accepted at $5 \%$ significance level.

\section{Diarrhea in children and stunting}

Descriptive analysis

Descriptive analysis provided that 24 children out of 440 children were affected with diarrhea with $5.5 \%$ prevalence of diarrhea in children between 2 years and below 5 years of age, as shown in Table 7. Moreover, 13 children out of 24 children with diarrhea were affected with stunting amounting to $54 \%$ prevalence of stunting in diarrhea inflicted children, as shown in Table 7. Children $(n=416 / 440)$ were normal and did not suffer from diarrhea. Out of 416 children, about $27 \%$ (113/416) children were stunted contributing to around $27 \%$ prevalence of stunting in children without diarrhea, as shown in Table 7. Other (11/24) 46\% children with diarrhea and (303/416) 73\% children without diarrhea were normal in height for age consideration. Prevalence of stunting (54\%) was almost doubled in children with diarrhea comparative to prevalence (27\%) of stunting in children without diarrhea.

\section{Correlation analysis}

Odds of being stunted were 1.18 in children with diarrhea, while the odds were 0.37 in children without diarrhea with a odds ratio of 3.2 at $95 \% \mathrm{CI}$ with the upper limit (1.28) and its lower limit (7.84) indicated about 3 times higher odds of being stunted in diarrhea group of children contrary to non-diarrhea group of children, as depicted in Table 7. Since the $95 \% \mathrm{CI}$ exceeded value $(>1)$, hence, correlation between diarrhea and stunting was significant at $\mathrm{p}=0.05$.

\section{Inferential analysis}

Test statistics yielded value $\left(\chi^{2}=8.09\right)$ and it was greater than table value $\left(\chi^{2}=3.84\right)$ at $\mathrm{df}=1$. In addition, significance level of test statistics $(p=0.009)$ was much lower than implied significance $(p=0.05)$, as shown in Table 7. Therefore, alternate hypothesis was accepted at $5 \%$ significance level.

\section{Income of family and stunting among children Descriptive analysis}

Descriptive analysis provided that income per month of $n=80 / 440$ families was below $<2000$ INR and other $n=360 / 440$ families had their income above $>2000$ INR per month, as shown in Table 8 . The 41 children out of 80 children who belonged to $<2000$ INR income of families were stunted and contributed to $51 \%$ prevalence of stunting, as shown in Table 8. Other group of children ( $n=85 / 360$ ) who belonged to ( $>2000$ INR) income of family, suffered from stunting. Prevalence $(23.6 \%)$ of stunting was observed in this group of children, as shown in Table 8. Children $(39 / 80)$ and $(275 / 360)$ belonging to income $(<2000$ INR) and $(>2000$ INR) per month of family, respectively, as in Table 8, were normal in height for age consideration. Prevalence (51\%) of stunting in children who belonged to ( $<2000$ INR) income of family per month was much higher in comparison to prevalence $(23.6 \%)$ of stunting in children who were from $>2000$ INR income group.

\section{Correlation analysis}

Odds (1.05) of becoming stunted in income of family ( $<2000$ INR) children and odds (0.309) of stunting in children who belonged to ( $>2000$ INR) income family per month, as shown in Table 8 were observed. The ratio of odds between former group and latter group was $\mathrm{OR}=3.4$ indicated that the probability of stunting in former group of children was around 3.4 times higher comparative to latter group of children and the probability was significant at $95 \% \mathrm{CI}$ having its upper limit (2.0) with lower limit (5.79) owing to $>1$ value of $95 \% \mathrm{CI}$, as depicted in Table 8. Hence, correlation between income of family and stunting prevalence of children was significant.

\section{Inferential analysis}

Test statistics yielded $\left(\chi^{2}=24.4\right)$ value and it was much higher in comparison to table value of Chi-square distribution $\left(\chi^{2}=3.84\right)$ at $\mathrm{df}=1$, as shown in Table 8. Further, significance value $(\mathrm{p}=0.001)$ of test statistics as much lower than the implied value $(\mathrm{p}=0.05)$. Therefore, at $5 \%$ significance level, alternate hypothesis was accepted.

\section{Illiteracy and stunting among children}

Descriptive analysis

In the child study population of total 440 children, about 90 children belonged to illiterate families, whereas, another 350 children belonged to literate families, as shown in Table 9. Out of 90 children of illiterate families, children $(n=35)$ were stunted with prevalence $38.9 \%$ of stunting in children. In literate families, children $(n=91 / 350)$ were stunted with $26 \%$ prevalence of stunting, as shown in Table 9.55 out of 90 and 259 out of 350 children of illiterate and literate families, respectively, were normal children. Prevalence of stunting (38.9\%) was higher in illiterate families in contrast to prevalence of stunting (26\%) in literate families' children.

\section{Correlation analysis}

Odds (0.636) of stunting in children who belonged to illiterate families were higher than odds (0.351) of being stunting in children of literate families and an odds ratio (OR=1.8) was computed, as shown in Table 9. Therefore, the children in illiterate families had 1.8 times higher possibility of becoming stunted than children in literate families and the correlation between illiteracy and stunting in children was significant at $95 \% \mathrm{CI}$ with its upper margin (1.08) to its lower margin (2.32).

Table 7: Diarrhea in children and stunting

\begin{tabular}{lll}
\hline Characteristics & $\begin{array}{l}\text { Children with } \\
\text { diarrhea }(\mathbf{n = 2 4})\end{array}$ & $\begin{array}{l}\text { Children without } \\
\text { diarrhea (n=416) }\end{array}$ \\
\hline Stunted children & $13(54 \%)$ & $113(27 \%)$ \\
Normal children & $11(46 \%)$ & $303(73 \%)$ \\
Odds ratio & 3.2 & \\
95\% Confidence interval & $1.28-7.84$ & \\
Chi-square value $\left(\chi^{2}\right)$ & 8.09 & \\
p $\leq 0.05$ & $0.009(\mathrm{HS})$ & \\
\hline
\end{tabular}

HS: Highly significant

Table 8: Income of family and stunting among children

\begin{tabular}{|c|c|c|}
\hline Characteristics & $\begin{array}{l}\text { Income of family } \\
(<2000 \text { INR) }(n=80)\end{array}$ & $\begin{array}{l}\text { Income of family } \\
(>2000 \text { INR) }(n=360)\end{array}$ \\
\hline Stunted children & $41(51 \%)$ & $85(23.6 \%)$ \\
\hline Normal children & $39(49 \%)$ & $275(75.4 \%)$ \\
\hline Odds ratio & 3.4 & \\
\hline $\begin{array}{l}95 \% \text { Confidence } \\
\text { interval }\end{array}$ & $2.0-5.79$ & \\
\hline $\begin{array}{l}\text { Chi-square } \\
\text { value }\left(\chi^{2}\right)\end{array}$ & 24.4 & \\
\hline $\mathrm{p} \leq 0.05$ & $<0.001$ (HS) & \\
\hline
\end{tabular}

HS: Highly significant

Table 9: Illiteracy and stunting among children

\begin{tabular}{lll}
\hline Characteristics & $\begin{array}{l}\text { Illiterate } \\
\text { families }(\mathbf{n}=\mathbf{9 0})\end{array}$ & $\begin{array}{l}\text { Literate } \\
\text { families }(\mathbf{n}=\mathbf{3 5 0})\end{array}$ \\
\hline Stunted children & $35(38.9 \%)$ & $91(26 \%)$ \\
Normal children & $55(61.1 \%)$ & $259(74 \%)$ \\
Odds ratio & 1.8 & \\
95\% Confidence interval & $1.08-2.32$ & \\
Chi-square value $\left(\chi^{2}\right)$ & 5.8 & \\
p $\leq 0.05$ & $0.01(S)$ & \\
\hline
\end{tabular}

S: Significant 


\section{Inferential analysis}

Chi-square test of independence was calculated with its value $\left(\chi^{2}=5.8\right)$ greater than critical value $\left(\chi^{2}=3.84\right)$ at degree of freedom $(\mathrm{df}=1)$. In addition, $p$ value of test statistics $(p=0.01)$ was lower than implied $(\mathrm{p}=0.05)$, as shown in Table 9. As a result, alternate hypothesis was accepted at $5 \%$ significance level.

\section{DISCUSSION}

Descriptive studies are essential to decipher hidden facts without any distortion in the information. The present study depicted an overall prevalence of $28.6 \%(126 / 440)$ of stunting among children between 2 years and below 5 years of age group in Fazilka city in Punjab, India. For the sake of comparison, a previous study by authors described almost similar trend in prevalence of stunting (26.7\%) in 2010 among children [10]. Stunting among children under five is subject to variation in accordance with region, state and nation. In a previous study, in Sri Lanka, a prevalence of $15 \%$ of stunting was observed among preschool children [11]. Still, another previous study was conducted among preschool children in Iran which depicted a prevalence $(12.5 \%)$ of stunting [12]. Further, previous study described a prevalence of $23.3 \%$ of stunting among under-five children in Southwest Kenya [13]. Hence, an unpredictable prevalence of stunting among under-five aged children is determined by an interplay of factors across the world. Worsening of availability and accessibility to food coupled with poor environmental factors, slacken the probability of good health and strongly favor undernutrition among preschool children.

In this study, children between 2 years and below 5 years of age, it was attempted to find out prevalence of stunting and predisposing factors for stunting. In the study population, slum children were represented by the smallest proportion (16.6\%) out of the three strata in city. The lowest proportion of slum children in the study population in present study was justified by a report by Census Commissioner of India Census [14]. According to it, in India, around 17.4\% population of city dwellers survived in slums. This report supplements the proportion of the slum children selected in this study. However, population of slum children is variable in accordance with the total population of city and other factors. According to similar report, the city of Mumbai holds the highest proportion (41.3\%) of slum dwellers, whereas, Delhi shelters around $14.6 \%$ population of slums [14].

In this study, boys and girls constituted $59 \%$ and $41 \%$ proportion of total proportion, respectively. Gender characterization of study population in present study is almost in accordance with the child sex ratio of the state of Punjab, India. Another report described the proportion of boys and girls [15]. According to it, boys in age group (0-6 years), constituted about 54\% proportion (1665994 boys out of 3076219 children), whereas girls in age group (0-6 years), accounted for nearly $45 \%$ proportion (1410225 girls out of 3076219 children) of the total population of children in the state of Punjab in India [15]. Further, it is asserted that mild variation in the proportion of boys and girls in the study population in comparison to sex child ratio of Punjab is attributed to wide fluctuation in child population across cities of Punjab, India. Therefore, Punjab population census data justified the proportion of boys and girls in this study group.

Study depicted overall literacy rate as prevalence of about $79.5 \%$ literacy and nearly $20.5 \%$ illiteracy among parents in study population. The literacy rate in present study is augmented by Punjab population Census data [15], accordingly, Punjab state holds a literacy rate of around $76 \%$. It is posited by author that minor difference in observed literacy in study population of present study and the one reported by Census of Punjab [15] is compensated by regional variations in literacy rate in the state of Punjab, India.

Age is an important determinant of stunting. Nutritional status of mother influences growth of fetus during intrauterine life and infant in early periods of postnatal life. In this study, children in age group
(2-3 years), suffered more than twice the higher probability of becoming stunted in comparison to children $(>3-<5$ years) age group. Previous study by authors supported higher prevalence of stunting in children in younger age group [16]. In the same study by authors involving children in urban area of Assis Brasil [16], it was found that about 17\% and 11\% of prevalence of stunting was observed in $2-3$ years and $>3-<5$ years age groups, respectively [16]. Findings of authors in study [16], supplements the findings of present study in the city Fazilka, India. According to a report, stunting can be predetermined from the nutritional status and hemoglobin level of adolescent girl who conceive in later life [7]. Stunting becomes worse if feeding and nursing are inadequate. As early as $2^{\text {nd }}$ year of life, stunting becomes irreversible [6].

Gender of child influences onset and progression of stunting. However, earlier descriptive and cross-sectional studies conducted by different researchers depicted conflicting results about the prevalence of stunting in boys and girls. In this study, girls had 35\% of stunting which was higher than the prevalence $(24 \%)$ of stunting in boys with statistical significance $(\mathrm{p}=0.01)$ and odds ratio (1.68). Moreover, previous studies by authors, confirmed higher prevalence of stunting in female children $[17,18]$. However, contrasting results were observed by authors in previous studies [16,19]. Moreover, previous studies by authors described equal prevalence of stunting in boys and girls [20-22].

Plausible explanation for gender based contradictory prevalence of stunting among children is the customary variations in nutritional status of mothers, care of baby, gender bias, medical health facility, sanitation and hygiene practices among families, which determine growth of children. It has been stated indisputably that women are disadvantaged in comparison to men in terms of food, security and health in household. There is a gender bias in the expenditure over food, distribution of food, and consumption of food in houses and is ubiquitous in all socioeconomic strata and is wide spread among cultures across the developing world [23-25]

Gender prejudice against girl child in food distribution, physical care, psychological nurturing is responsible for higher rate of malnutrition in children, as was observed in present study by author.

Social stratification into different socioeconomic strata, essentially, affects the growth and development of children in households and learning ability of children in schools. In this study, study population was categorized into schools, child care centers, and slums. Slums represented the highest (48\%) proportion of stunting among children with high statistical significance $(\mathrm{p}=0.0002)$. Prevalence of stunting among children in schools and child care centers was almost comparable ( $23 \%$ and $28 \%)$.

Previous study by authors among primary school children in Nigerian city projected a highly significant association between slum children and malnutrition [26]. Another previous study by authors predicted a significant correlation between area of inhabitation of children (ruralurban) and undernourishment of children [27]. Still, another previous study by authors on preschool children in Democratic Yemen, proved a strong relation between slum children and malnutrition [28].

Slums are discriminated from urban and rural areas by poverty, illiteracy, food insecurity, unpredictable income sources and indifference to sanitation and hygiene. Slums are characterized by maternal undernourishment, diseases, neonatal and postnatal affliction with preventable diseases and impairment of growth and development of the nascent generation of mankind.

Anemia is characterized by a reduction in hemoglobin concentration and or a decrease in the RBC count below a reference value. This clinical condition is marked by multiple manifestations such as nausea, vomiting, reduced appetite, bowel disturbance, hypotension, and lethargy. Anemia in remote setting is probably a result of either iron 
deficiency or deficiency of cobalamin and folic acid or a chronic disease in body. This study illustrated higher prevalence $(36.5 \%)$ of stunting among anemic children in comparison to prevalence (25\%) of stunting among non-anemic children and indicated almost twice (1.65) the higher likelihood of stunting among anemic children. Previous study by authors [29] found a significant correlation between anemia and stunting among preschool children with an odds ratio (1.66), which is strongly equal to odds ratio observed in present study (1.65) between anemia and stunting. Therefore, former study [29] augments the findings in this study.

Another previous study among preschool children in Kuwait [30], it was observed that odds of having stunting in anemic children were twice the times higher than the probability of stunting in non-anemic children.

Nutritional anemia is common among preschool children and women during pregnancy and lactation, especially, in rural population and slum dwellers. Periods of rapid growth and/or physiological condition, warrants high requirement of iron for the metabolic activities in body. Inadequate diet and or consumption of poor quality of food might be an important predisposing factors for anemia, wasting, and stunting and other nutritional disorders among preschool children.

Geophagy is the incessant behavior of eating non-nutritive substances by preschool children. Soil eating may prove disastrous for the growth and development of children under five. In this study, high prevalence of stunting (51\%), almost thrice the times higher ( $\mathrm{OR}=2.9$ ), was observed in children habitual of soil eating in contrast to (26\%) prevalence of stunting among children not habitual of soil eating. Moreover, previous study asserted a significant relation between geophagy in children and stunting [31] and it depicted 2 times higher odds of stunting in soil eating children, hence, the previous study [31] supported the findings of present study and delineates an important correlation between soil eating habit and stunting among children.

One more previous study [32] posited a relation between soil eating and stunting among children and authenticates the data in present study.

Diarrhea is a leading cause of mortality and morbidity among children below five. Vital body fluids are wasted with each successive diarrheal attack resulting in physical emaciation and immunity compromised growth and development of children. In this study, 300\% (OR=3.2) times higher chances of stunting were observed in children who had diarrheal episodes in the preceding 2 weeks interval in comparison to children who had no diarrheal episodes. Previous study [21] described $(\mathrm{OR}=4.18) 4$ times higher chances of stunting in diarrheal children, therefore, findings of previous study are in agreement with findings in present study, thereby, proving a significant correlation between diarrhea and stunting in children.

Other evidence was provided by authors in a previous study [33], which described $47.6 \%$ prevalence of stunting among children which was significantly associated with diarrhea.

Possibly, higher prevalence of stunting in children with diarrheal tendency is due to chronic deficiency of necessary macronutrients and minerals for ensuring the growth and development in preschool age. Stunting describes the prolonged hunger for nutrition. Diarrhea impairs the body ability to absorb the vital contents of food despite adequate intake of diet resulting into chronic malnutrition.

Education of parents and monthly income in a household are vital characteristics which influence the nutritional status of children. Illiteracy and poor monthly income become the limiting factor in the search for better livelihood, social status, care of infants, food for infants, education, and health of children. In this study, almost double probability of stunting and more than 3 times higher chances of stunting were observed in children whose parents were illiterate and earned a monthly income $(<2000$ INR). Previous study proved a highly significant relation between low monthly income and stunting in children [34].

Another previous study proved a correlation between high socioeconomic status of parents and low prevalence of stunting in children [17]. Another earlier study posited a positive correlation between illiteracy, low monthly income ( $<$ US \$20) and stunting among children [20]

Hence, these previous studies authenticate the findings related to correlation among illiteracy, low monthly income and stunting among children, in this study [36,37]

\section{CONCLUSION}

Poverty, illiteracy, lack of motivation, improper sanitation and poor hygiene practice dissuade the normal growth and development among children during early childhood. These factors operate strongly in rural population and slums in comparison to urban population. Persistent, cooperative, and honest efforts are necessary to ameliorate the sufferings the children are facing across the world.

\section{REFERENCES}

1. Black RE, Victora CG, Walker SP, Bhutta ZQ, Christian P, Onis M, et al. Maternal and child under nutrition and overweight in low-income and middle-income countries. Lancet 2013;382(9890):427-51.

2. The World Bank. Poverty Overview; 2012. Available from: http://www. worldbank.org/en/topic/poverty.

3. Kosek M, Bern C, Guerrant RL. The global burden of Diarrhoeal disease, as estimated from studies published between 1992 and 2000. Bull World Health Organ 2003;81:197-204.

4. Scrimshaw NS, Taylor CE, Gordon JE. Interactions of nutrition and infection. Monogr Ser World Health Organ 1968;57:3-329.

5. Mata LJ, Kronmal RA, Urrutia JJ, Garcia B. Antenatal events and postnatal growth and survival of children in a rural Guatemalan village. Ann Hum Biol 1976;3(4):303-15.

6. Schlaudecker EP, Steinhoff MC, Moore SR. Interactions of diarrhea, pneumonia, and malnutrition in childhood: Recent evidence from developing countries. Curr Opin Infect Dis 2011;24(5):496-502.

7. UNICEF. Stunting and Diarrhoea. Available from: http://unicef.in/ Whatwedo/10/Stunting. [Last retrieved on 2016].

8. WHO, Multicentre Growth Reference Study Group. WHO Child Growth Standards based on length/height, weight and age. Acta Paediatr Suppl 2006;450:76-85.

9. World Health Organization. Definitions of Indicators for Child Anthropometry. WHO; 2010. Available from: http://www.who.int/ nutrition/nlis_interpretation_guide.pdf.

10. De Onis M, Blossner M, Borghi E. Prevalence and trends of stunting among pre-school children 1990-2020. Public Health Nutr 2011;1 7. Available from: http://www.who.int/nutgrowthdb/publications/ Stunting1990 2011.pdf.

11. Thamilini J, Silva KD, Jayasinghe JM. Prevalence of stunting among pre-school children in food insecure rural households in Sri Lanka. Trop Agric Res 2015;26(2):390-4.

12. Payandeh A, Saki A, Safarian M, Tabesh H, Siadat Z. Prevalence of malnutrition among preschool children in northeast of Iran, a result of a population based study. Glob J Health Sci 2013;5(5):208-12.

13. Shinsugi C, Matsumura M, Karama M, Tanaka J, Changoma M, Kaneko $\mathrm{S}$, et al. Factors associated with stunting among children according to the level of food insecurity in the household: A crosssectional study in a rural community of Southeastern Kenya. BMC Public Health 2015; $15: 441$.

14. Census Commissioner of India Census. Census of India; 2011. Available from: http://www.censusindia.gov.in/2011census/PCA/ PCA Highlights/pca highlights file/India/Chapter-1.pdf.

15. Punjab Population Census Data. Punjab Population; 2011. Available from: http://www.census2011.co.in/census/state/punjab.html.

16. Olwedo MA, Mworozi E, Bachou H, Orach CG. Factors associated with malnutrition among children in internally displaced person's camps, northern Uganda. Afr Health Sci 2008;8(4):244-52.

17. Khuwaja S, Selwyn BJ, Shah SM. Prevalence and correlates of stunting among primary school children in rural areas of southern Pakistan. J Trop Pediatr 2005;51(4):72-7.

18. Sengupta P, Philip N, Benjamin AI. Epidemiological correlates of 
under-nutrition in under five children in an urban slum of Ludhiana. Health Popul Perspect Issues 2010;33(1):1-9.

19. Asfaw M, Wondaferash M, Taha M, Dube L. Prevalence of under nutrition and associated factors among children aged between six to fifty nine months in Bule Hora district, South Ethiopia. BMC Public Health $2015 ; 15: 41$.

20. Zelellw DA, Gebreigziabher BG, Alene KA, Negatie BA, Kasahune TA. Prevalence and associated factors of stunting among schoolchildren, in Debre Markos town and Gozamen woreda, East Gojjam Zone, Amhara Regional State, Ethiopia. J Nutr Food Sci 2014;S8:7.

21. Paudel R, Pradhan B, Wagle RR, Pahari DP, Onta SR. Risk factors for stunting among children: A community based case control study in Nepal. Kathmandu Univ Med J (KUMJ) 2012;10(39):18-24.

22. Alasfoor D, Elsayed MK, Al-Qasmi AM, Malankar P, Sheth M, Prakash N. Protein-energy malnutrition among preschool children in Oman: Results of a national survey. East Mediterr Health J 2007;13(5):1022-30

23. Hadley C, Lindstrom D, Tessema F, Belachew T. Gender bias in the food insecurity experience of Ethiopian adolescents. Soc Sci Med 2008;66(2):427-38.

24. Smith LC. The Importance of Women Status for Child Nutrition in Developing Countries. Washington, DC: International Food Policy Research Institute; 2003.

25. Spieldoch A. The Right to Food, Gender Equality and Economic Policy. New Brunswick: Center for Women's Global Leadership, CWGL; 2011.

26. Ndukwu CI, Egbuonu I, Ulasi TO, Ebenebe JC. Determinants of under nutrition among primary school children residing in slum areas of a
Nigerian city. Niger J Clin Pract 2013;16(2):178-83.

27. Dutta A, Pant K, Puthia R, Sah A. Prevalence of undernutrition among children in the Garhwal Himalayas. Food Nutr Bull 2009;30(1):77-81.

28. Bågenholm G, Kristiansson B, Nasher AA. Growth and malnutrition among preschool children in Democratic Yemen. Bull World Health Organ 1988;66(4):491-8.

29. Awasthi S, Das R, Verma T, Vir S. Anemia and under nutrition among preschool children in Uttar Pradesh, India. Indian Pediatr 2013;40(10):985-90.

30. Al-Qaoud NM, Al-Shamil E, Prakash P. Anemia and associated factors among Kuwaiti preschool children and their mothers. Alex J Med 2015;51(2):161-6.

31. George CM, Oldja L, Biswas S, Perin J, Lee GO, Kosek M, et al. Geophagy is associated with environmental enteropathy and stunting in children in rural Bangladesh. Am J Trop Med Hyg 2015;92(6):1117-24.

32. Diouf S, Camara B, Sall MG, Diagne I, Ndiaye O, Diallo A, et al. Protein-energy malnutrition in children less than five years old in a rural zone in Senegal (Khombole). Dakar Med 2000;45(1):48-50.

33. Ricci KA, Girosi F, Tarr PI, Lim YW, Mason C, Miller M, et al. Reducing stunting among children: The potential contribution of diagnostics. Nature 2006;444 Suppl 1:29-38

34. Chesire EJ, Orago AS, Oteba LP, Echoka E. Determinants of under nutrition among school age children in a Nairobi Peri-Urban slum. East Afr Med J 2008;85(10):471-9.

35. Kongawad P, Boodeppa GK. National family planning programmeduring the five year plans of India. J Evol Med Dent Sci 2014;3:5172-8.

36. Crichton J. Changing fortunes: Analysis of fluctuating policy space for family planning in Kenya. Health Policy Plan 2008;23(5):339-50. 